Reprod. Nutr. Dévelop., 1988, 28 (1), 127-128.

\title{
Influence du régime alimentaire sur la population fongique anaérobie du rumen
}

\author{
Elisabeth GRENET, A. BRETON $\left({ }^{*}\right)$, G. FONTY $\left({ }^{*}\right)$, P. BARRY, B. RÉMOND $(* *)$ \\ Laboratoire des Aliments. \\ $\left({ }^{*}\right)$ Laboratoire de Microbiologie. \\ (**) Laboratoire de la Lactation, \\ I.N.R.A., Theix, 63122 Ceyrat, France.
}

Summary. The colonization of plant tissues by anaerobic rumen fungi was investigated on a rumen fistulated cow fed different diets. The fungae population tended to decrease with a diet rich in starch (barley) or in sugar (beets or whey). The colonization of the sugar beet pulp occurred only when the cow was fed a maize silage diet.

L'étude ultrastructurale de la dégradation microbienne des parois végétales dans le rumen a montré que la présence de champignons sur les tissus semblait dépendre du régime alimentaire de l'animal et du substrat étudié (Grenet et Barry, 1987a) ; c'est ce que nous avons voulu approfondir dans le présent travail.

Matériel et méthodes. Une vache porteuse d'une canule du rumen a successivement reçu, au cours de périodes de 3 à 6 semaines, les régimes suivants : 1) ensilage de maïs $(5,6 \mathrm{~kg}$ de matière sèche $\mathrm{MS} / \mathrm{j})$, concentré énergétique $(4,6 \mathrm{~kg}$ de $\mathrm{MS} / \mathrm{j})$ et tourteau tanné de colza et de soja $(0,4 \mathrm{~kg}$ de $\mathrm{MS} / \mathrm{j}) ; 2)$ orge broyée $(6,8 \mathrm{~kg}$ de $M S / \mathrm{j})$, ensilage de mais $(1,7 \mathrm{~kg}$ de $\mathrm{MS} / \mathrm{j})$ et tourteau tanné de colza et de soja $(0,4 \mathrm{~kg}$ de $M S / j) ; 3)$ betteraves $(8,2 \mathrm{~kg}$ de $M S / j)$ et foin de luzerne $(7,4 \mathrm{~kg}$ de $\mathrm{MS} / \mathrm{j}) ; 4)$ lactosérum doux en poudre $(7,8 \mathrm{~kg}$ de $\mathrm{MS} / \mathrm{j})$, foin de luzerne $(6,2 \mathrm{~kg}$ de $M S / \mathrm{j})$ et pulpe de betteraves déshydratée $(0,9 \mathrm{~kg}$ de $\mathrm{MS} / \mathrm{j})$; 5) ensilage de maïs $(12,1 \mathrm{~kg}$ de $\mathrm{MS} / \mathrm{j})$ et urée $(0,145 \mathrm{~kg}$ de $\mathrm{MS} / \mathrm{j})$. Les régimes $n^{\circ s} 1,2,3$ et 4 ont été distribués en deux repas par jour mais avec une répartition inégale des aliments pour le régime $n^{\circ} 3$, les betteraves étant distribuées en totalité le matin et le foin le soir ; seul le régime $n^{\circ} 5$ a été distribué en une seule fois, le matin. Au cours de la dernière semaine de chaque période les zoospores ont été dénombrées dans le liquide du rumen $2 \mathrm{~h}$ après la distribution des aliments du matin par la méthode des roll-tubes. Par ailleurs, pour estimer la vitesse de colonisation des tissus et de développement des sporocystes des sachets de nylon contenant 5 fragments de $5 \mathrm{~mm}$ chacun de pulpe de betteraves déshydratée (B), tégument de soja $(T)$, tige de maïs $(M)$ et tige de luzerne (L), ont été placés dans le rumen juste avant la distribution des aliments et retirés $2 \mathrm{~h}, 6 \mathrm{~h}$ ou $24 \mathrm{~h}$ après. Ces substrats ont été choisis pour leur structure histologique différente d'une part 
et pour leur plus ou moins grande aptitude à être colonisés d'autre part (Grenet et Barry, 1987b). Le $\mathrm{pH}$ du liquide du rumen a été mesuré à chaque introduction ou retrait des sachets.

Résultats et discussion. Les champignons anaérobies sont abondants dans le rumen avec les régimes d'ensilage de maïs distribués avec ou sans concentré (tabl. 1). Ils se raréfient avec le régime riche en orge et dans ce cas leur maintien dans le rumen n'est révélé que par la colonisation des substrats in sacco. Cet appauvrissement est manifeste aussi pour le régime à base de betteraves $(\mathrm{pH}$ $5,40)$ pour lequel on n'observe même plus de colonisation des substrats in sacco mais seulement des champignons dans les cultures in vitro. Aucun champignon n'est observé avec le régime lactosérum, mais ils réapparaissent avec un niveau de population élevé avec le régime d'ensilage de maïs. Au total leur présence est associée à un $\mathrm{pH}$ du jus de rumen compris entre 6,5 et 7,3 .

TABL. 1. $-p H d u$ jus de rumen après la pose des sachets; dénombrement et identification des champignons dans le jus de rumen $2 \mathrm{~h}$ après la distribution du repas; colonisation des substrats in sacco et dimensions moyennes de 10 sporocystes environ $(\mu \mathrm{m})$ après $24 \mathrm{~h}$ de séjour dans le rumen.

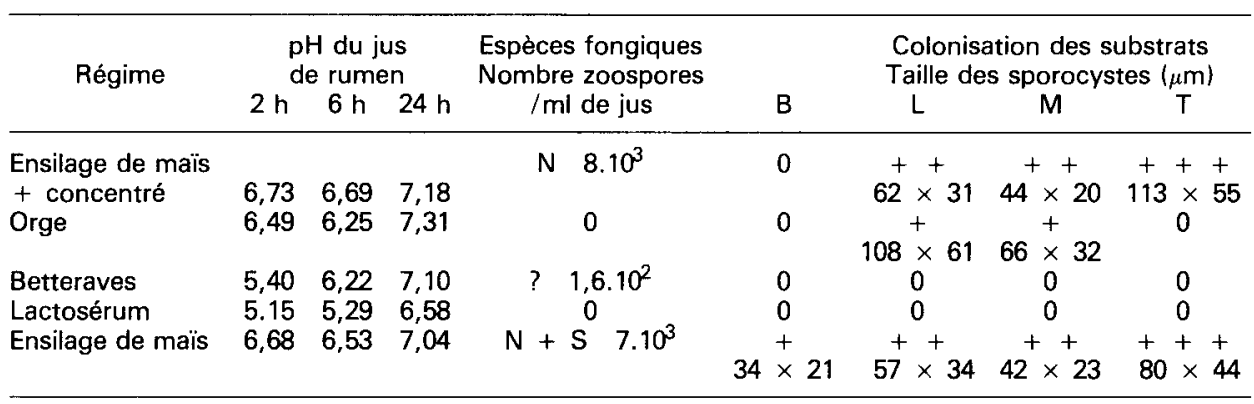

$\mathrm{N}$ : Neocallimastix ; $\mathrm{S}$ : Sphaeromonas ; $\mathrm{B}$ : pulpe de betteraves déshydratée ; $\mathrm{L}$ : tige de luzerne ; $M$ : tige de maïs ; $T$ : tégument de graine de soja ;

$\mathrm{O}$ : absence $;+$ peu abondante $;++$ abondante $;+++$ très abondante.

Lorsque le régime est favorable à la colonisation des substrats la fixation des zoospores s'effectue dès les deux premières heures, mais la densité des populations fongiques et le degré de développement des sporocystes après $24 \mathrm{~h}$ varient suivant le substrat; les téguments de graine de soja sont toujours fortement colonisés et sur ce substrat on note une accélération du cycle de reproduction comme en témoignent les dimensions moyennes élevées des sporocystes. Les substrats peuvent être classés suivant la taille décroissante des sporocystes de la façon suivante : téguments de graine de soja, tiges de luzerne, tiges de maïs, pulpes de betteraves.

En conclusion la présence, le nombre de champignons anaérobies dans le rumen et la fixation des zoospores sur les substrats végétaux dépendent donc du régime alimentaire.

Remerciements. - Ce travail a été réalisé en partie grâce à un financement accordé dans le cadre du GIS sur "l'étude de la cellulolyse dans le rumen et dans un digesteur ».

Grenet E., Barry P., 1987a. Reprod. Nutr. Dévelop., 27, 246-247.

Grenet E., Barry P., 1987b. Anim. Feed Sci. Technol. (sous presse). 